\title{
Rapid Annealing Effects on Microstructure, Texture, and Magnetic Properties of Non-Oriented Electrical Steel
}

\author{
Jian Wang ${ }^{1,2}$, Jun $\mathrm{Li}^{2}$, Xiaochuan $\mathrm{Mi}^{2}$, Shengen Zhang ${ }^{1, *}$, and Alex A. Volinsky ${ }^{4}$ \\ ${ }^{1}$ School of Materials Science and Engineering, University of Science and Technology Beijing, \\ Beijing 100083, China \\ ${ }^{2}$ Baoshan Iron \& Steel Co. Ltd., Shanghai 200941, China \\ ${ }^{3}$ Department of Mechanical Engineering, University of South Florida, Tampa FL 33620, USA
}

(received date: 27 September 2010 / accepted date: 21 February 2011)

\begin{abstract}
This paper presents a classic process-structure-properties approach for optimizing the magnetic properties of electrical steels. Cold-rolled non-oriented electrical steel (Fe; $0.001 \mathrm{wt} \% \mathrm{C} ; 0.2 \mathrm{wt} \% \mathrm{Mn} ; 1.3 \mathrm{wt} \% \mathrm{Si}$ ) was subjected to extremely short 3-30 seconds annealing cycles in a range from $880^{\circ} \mathrm{C}$ to $980{ }^{\circ} \mathrm{C}$ with a heating rate varying from $15^{\circ} \mathrm{C}$ to $300^{\circ} \mathrm{C} / \mathrm{sec}$. The resulting microstructure was studied by means of optical microscopy and X-ray orientation distribution function analysis. Recrystallized grains were refined with increased heating rate, caused by the nucleation rate increase, which is faster than the growth rate due to rapid heating. The optimal grain size of 60 to $80 \mathrm{~mm}$ in terms of magnetic properties was obtained by increasing the annealing temperature range to $920{ }^{\circ} \mathrm{C}$ to $940{ }^{\circ} \mathrm{C}$ with a higher heating rate of $300{ }^{\circ} \mathrm{C} / \mathrm{sec}$ and an annealing time of 6 to 9 seconds. With the heating rate increase, the characteristic $\{111\}$ recrystallization fiber of cold-rolled steel was depressed, but the beneficial $\{110\}<001>$ Goss texture component was significantly strengthened. The recrystallized grain size and texture were enhanced by rapid annealing, and, as a result, the magnetic properties of non-oriented electrical steel improved.
\end{abstract}

Key words: non-oriented electrical steel, rapid annealing, recrystallized grain size, recrystallization texture, orientation distribution function (ODF), magnetic properties

\section{INTRODUCTION}

Non-oriented electrical steel is one of the most important soft magnetic materials, which is generally used to conduct magnetic flux inside electromagnetic components in rotational electric machines. Recently, there have been many studies focused on developing improved grades of electrical steels, driven by world-wide efforts to reduce energy consumption and protect the global environment $[1,2]$.

In general, the magnetic properties of cold-rolled non-oriented electrical steels mainly depend on their grain size and texture [3]. Grain size and texture are also critical factors determining the iron loss and magnetic induction in non-oriented electrical steels. Grains with easy magnetic direction texture components can increase magnetic induction [4], although grain size has an opposite effect on hysteresis and eddy current losses. Thus, there is an optimal grain size, which can help minimize the sum of hysteresis and eddy current losses, about 80 to $100 \mu \mathrm{m}$ for slow heating rates of $1 \mathrm{wt} . \%$ $\mathrm{Si}$ steel [5]. In addition, the optimal grain size changes with

*Corresponding author: zhangshengen@mater.ustb.edu.cn CKIM and Springer, Published 20 June 2012 chemical composition and texture [6,7].

During the final annealing, process parameters, such as heating rate, annealing temperature, annealing time, and cooling rate, are the key factors determining the final grain size and texture of non-oriented electrical steel, ultimately affecting its magnetic properties. It is well-known that the heating rate has a strong effect on grain size and texture evolution through changes in recovery and recrystallization behavior during the final annealing treatment [8]. Some researchers have studied the relationship between annealing parameters and recrystallized microstructure. Grain orientation changes during nucleation and growth processes have been reported by Verbeken et al. [9] and Sebald and Gottstein [10]. Moseley et al. [11] and Cunha and Paolinelli [12] studied the effects of the final annealing temperature on non-oriented electrical steel microstructure evolution. As expected, they found that the average grain size increases with increased annealing temperature. Baudouin et al. [13] believe that electrical steel magnetic properties deteriorate due to thermal stresses caused by high heating rates ranging from 1500 to $3000{ }^{\circ} \mathrm{C} / \mathrm{s}$. Bae et al. [14] found that the mean grain size became larger and the favorable texture was weakened when the heating rate was increased from $12.5^{\circ} \mathrm{C} / \mathrm{s}$ to $21.5^{\circ} \mathrm{C} / \mathrm{s}$. On the other hand, 
Duan et al. [15] and Park et al. [16] reported that a heating rate increase in the 5 to $30^{\circ} \mathrm{C} / \mathrm{s}$ range has a favorable effect on the magnetic properties and recrystallized microstructure because it changes the recovery and recrystallization processes in electrical steel. In earlier studies, the heating rate was either in the range from 5 to $30^{\circ} \mathrm{C} / \mathrm{s}$, or above $1000^{\circ} \mathrm{C} / \mathrm{s}$. However, the heating rate range of 15 to $300^{\circ} \mathrm{C} / \mathrm{s}$, which can now be easily achieved in industry, was unfortunately ignored. Therefore, in this study, non-oriented electrical steel was subjected to rapid annealing with the heating rate ranging from 15 to $300^{\circ} \mathrm{C} / \mathrm{s}$. Correlations between rapid annealing parameters and optimal recrystallized grain size and texture were established to improve the grade of non-oriented electrical steel and its magnetic properties by means of rapid annealing.

\section{EXPERIMENTAL PROCEDURES}

Fast heating experiments were carried out on industriallymanufactured non-oriented electrical steel with $0.001 \mathrm{wt} \%$ $\mathrm{C}, 0.2 \mathrm{wt} \% \mathrm{Mn}$, and $1.3 \mathrm{wt} \% \mathrm{Si}$, which was cold rolled to the final thickness of $0.5 \mathrm{~mm}$ through the reduction ratio of $85 \%$.

Specimens with $300 \mathrm{~mm} \times 600 \mathrm{~mm} \times 0.5 \mathrm{~mm}$ dimensions were cut from the cold-rolled steel sheet and annealed between $880{ }^{\circ} \mathrm{C}$ and $980{ }^{\circ} \mathrm{C}$ for 3 to 30 seconds in $30 \% \mathrm{H}_{2}-70 \% \mathrm{~N}_{2}$ dry atmosphere using a laboratory annealing machine by high-intensity electrical current heating. Fig. 1(a) shows the scheme of the experimental setup. The heating rates were 15 , $50,100,200$, and $300^{\circ} \mathrm{C} / \mathrm{s}$, and the cooling rate was $28^{\circ} \mathrm{C} / \mathrm{s}$, controlled by $\mathrm{H}_{2}$ flow in the oven.

The thermal cycle was recorded with a computer-controlled device using calibrated infrared temperature sensors and five calibrated thermocouples welded on each sample. The temperature cures during heating of the samples to $880^{\circ} \mathrm{C}$ at $50{ }^{\circ} \mathrm{C} / \mathrm{s}$ and $300^{\circ} \mathrm{C} / \mathrm{s}$ are presented in Fig. 1(b) and (c).

The lower heating rate of $50^{\circ} \mathrm{C} / \mathrm{s}$ (Fig. 1b) can be controlled accurately so that the curve of temperature-time is close to a beeline. When heating rate is increased to $300^{\circ} \mathrm{C} / \mathrm{s}$, the heating rate drops appreciably when temperature approaches the setting temperature to avoid the effect of overshooting the peak temperature. During heating, the ratio of temperature to time is close to $300^{\circ} \mathrm{C} / \mathrm{s}$. The heating curve shows that the samples suffered from overheating from about $20^{\circ} \mathrm{C}$ to $900{ }^{\circ} \mathrm{C}$ in $1 \mathrm{~s}$ when the temperature was close to the setting temperature of $880{ }^{\circ} \mathrm{C}$.

The microstructure of the specimens was observed to be parallel to the rolling using an optical microscope (DM ILM Leica, Germany). Etching solution (2\% natal) was utilized to bring out the microstructure. The size of more than 200 random grains was measured by using the standard linear intercept method. The texture of the specimens was detected using a RIGAKU RINT2500/PC X-ray diffractometer under

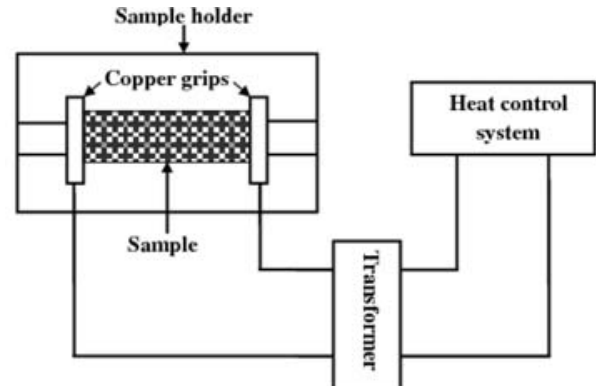

(a)

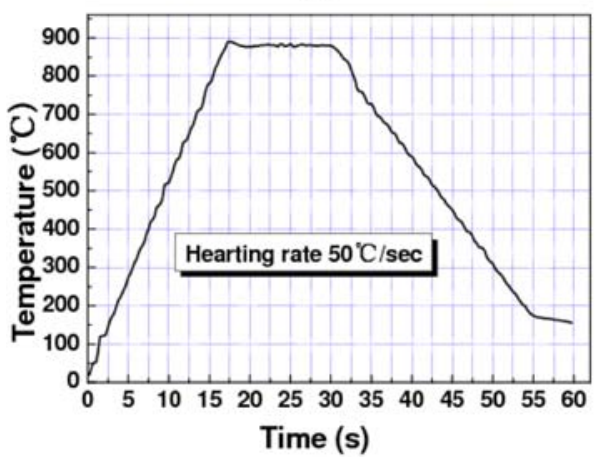

(b)

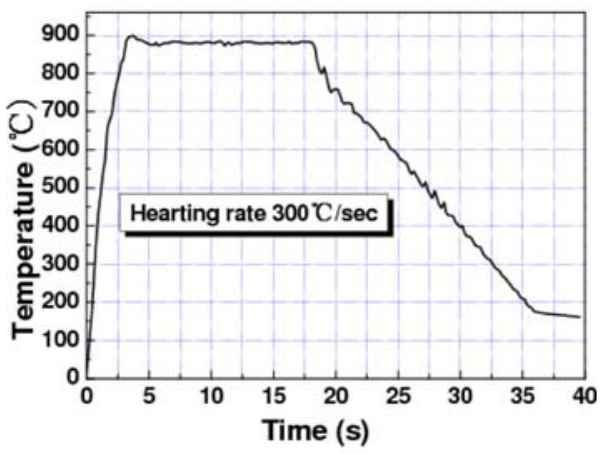

(c)

Fig. 1. (a) Scheme of rapid heating experimental setup; thermal cycle of treated samples with (b) $50^{\circ} \mathrm{C} / \mathrm{s}$ and (c) $300^{\circ} \mathrm{C} / \mathrm{s}$.

$50 \mathrm{kV}$ and $200 \mathrm{~mA}$ with Mo radiation. The top surfaces of the specimens were polished by $60 \mu \mathrm{m}$ and three incomplete $\{110\},\{100\}$, and $\{211\}$ pole figures were obtained. The orientation distribution function (ODF) was evaluated from the three pole figures using the Bunge series expansion method. Magnetic properties were measured by the Epstein frame using eight $180 \mathrm{~mm} \times 30 \mathrm{~mm} \times 0.5 \mathrm{~mm}$ pieces cut from larger annealed samples. Magnetic induction at $5000 \mathrm{~A} / \mathrm{m}$ $\left(\mathrm{B}_{50}\right)$ and core losses at $1.5 \mathrm{~T}$ and $50 \mathrm{~Hz}\left(\mathrm{P}_{1.5 / 50}\right)$ were measured. Measurement errors were $\pm 1 \%$ for $\mathrm{P}_{1.5 / 50}$ and $\pm 0.5 \%$ for $\mathrm{B}_{50}$.

\section{RESULTS AND DISCUSSION}

\subsection{Recrystallized grain size}

Figure 2 shows the microstructure of recrystallized specimens annealed at $880^{\circ} \mathrm{C}$ and $980^{\circ} \mathrm{C}$ for 3 seconds with heat- 


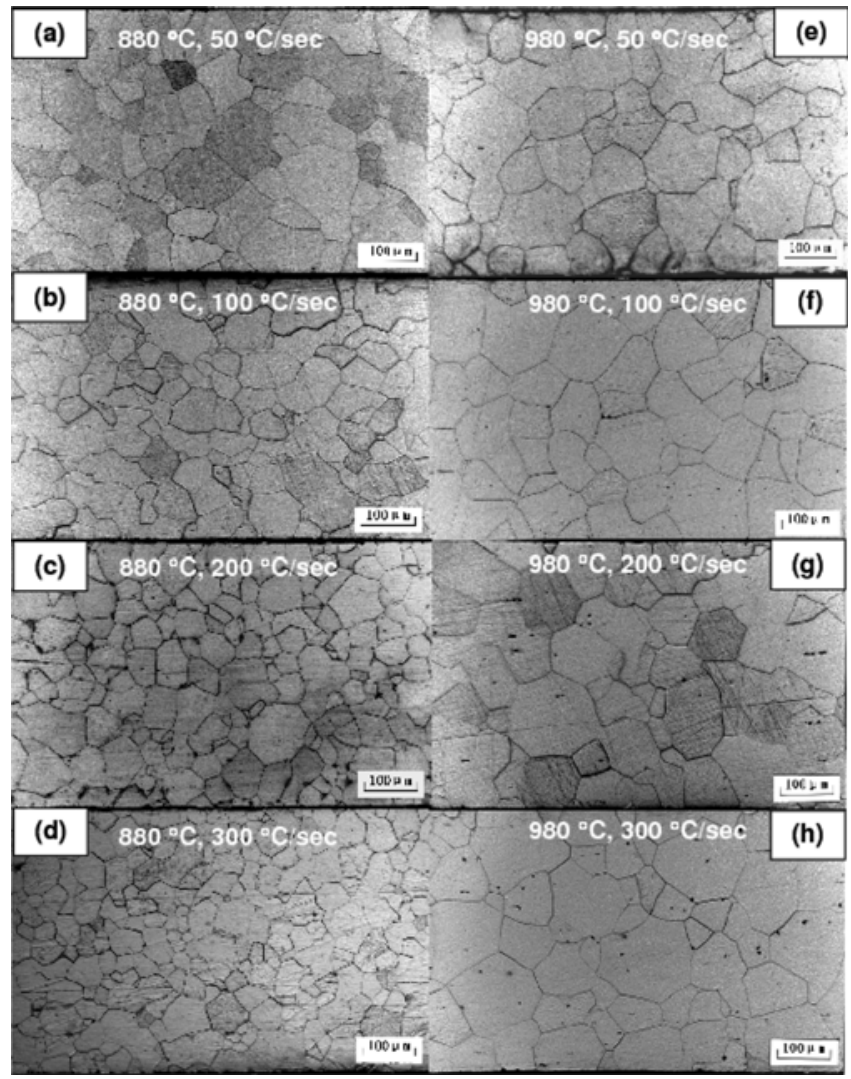

Fig. 2. Optical micrographs $\left(100^{\circ}\right)$ of specimens annealed at $880^{\circ} \mathrm{C}$ and $980{ }^{\circ} \mathrm{C}$ for 3 seconds with various heating rates: a) $880^{\circ} \mathrm{C}, 50^{\circ} \mathrm{C} /$ sec, b) $100{ }^{\circ} \mathrm{C} / \mathrm{s}$, c) $200{ }^{\circ} \mathrm{C} / \mathrm{s}$, d) $300^{\circ} \mathrm{C} / \mathrm{s}$, e) $980{ }^{\circ} \mathrm{C}, 50{ }^{\circ} \mathrm{C} / \mathrm{s}$, f) $100{ }^{\circ} \mathrm{C} /$ s, g) $200^{\circ} \mathrm{C} / \mathrm{s}$, h) $300^{\circ} \mathrm{C} / \mathrm{s}$.

ing rates ranging from 50 to $300^{\circ} \mathrm{C} / \mathrm{s}$. The microstructure is composed of equiaxed grains which completely replaced the cold-rolled deformation texture, meaning that recrystallization was complete. A decreasing trend in recrystallized grain size was found with the heating rate increase from 50 to $300^{\circ} \mathrm{C} / \mathrm{s}$, as shown in Figs. 2a-d, for the annealing temperature of $880^{\circ} \mathrm{C}$. However, grain size stayed almost unchanged when the annealing temperature was $980^{\circ} \mathrm{C}$ as seen in Figs. 2e-h.

Figure 3 shows the effects of the heating rate and annealing temperature on the recrystallized grain size with $3 \mathrm{sec}-$ onds annealing time. The mean grain size decreases with heating rate because the recrystallized grain size is controlled by both the nucleation rate in deformed matrices and the nuclei growth rate [17]. In the rapid annealing process, the cold-rolled stored elastic energy is partially preserved during rapid heating, opposite to the slow heating before recrystallization commencing. Although both nucleation and growth rates increase due to high stored strain energy, the increase in the nucleation rate is faster than that of the growth rate. Therefore, compared with slow annealing, rapid annealing leads to smaller grain size, which agrees with the results from previous studies [15,18].

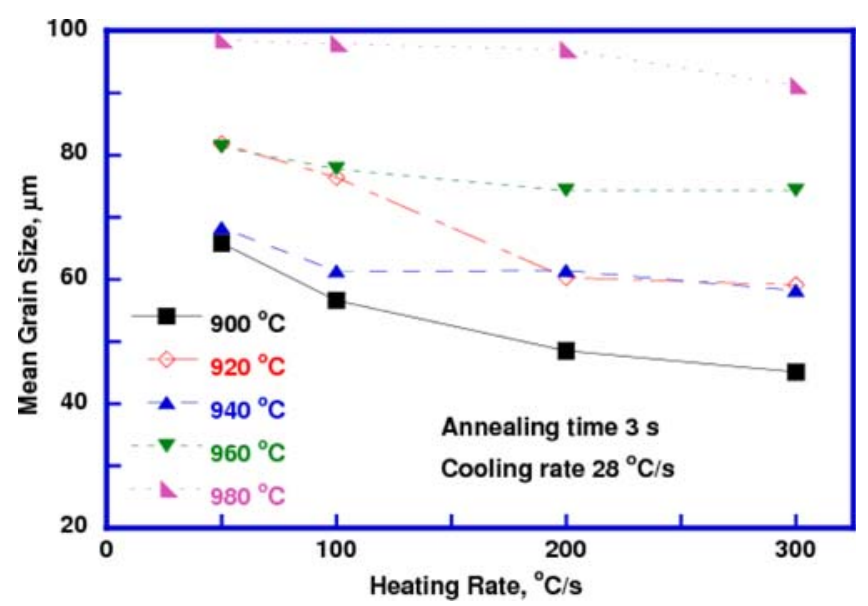

Fig. 3. Heating rate and annealing temperature effects on the mean grain size.

Grain size decreases sharply with the heating rate for samples annealed at $880^{\circ} \mathrm{C}$. In addition, for a given heating rate, the mean grain size increases with the annealing temperature. This is because the annealing temperature could increase the grain growth rate, and then grain refinement caused by rapid heating can be weakened by increased annealing temperature. In this paper, the optimal grain size of about 60 to $80 \mu \mathrm{m}$ was obtained by annealing samples above $920^{\circ} \mathrm{C}$ at $300^{\circ} \mathrm{C} / \mathrm{s}$ for 6 to 9 seconds.

\subsection{Heating rate effect on recrystallized microstructure}

Figure 4 shows the recrystallized texture of $\varphi_{2}=45^{\circ}$ ODF section at various heating rates. It can be seen that when the annealing temperature of $880^{\circ} \mathrm{C}$ was applied for 15 seconds and the heating rate was varied from 15 to $300^{\circ} \mathrm{C} / \mathrm{s}$, the main recrystallized texture was $\gamma$-fiber, and the preferred orientations mostly concentrated along the $\{111\}<110>$ and $\{111\}<112>$ directions. With increased heating rate, the intensity of $\{111\}<110>$ and $\{111\}<112>$ texture components decreased, and that of the Goss component increased. During the annealing process, recrystallized texture evolution depends on the nucleation and growth rates of different orientations, which have various amounts of stored elastic energy [19]. Recrystallization nuclei mainly concentrate on regions with high stored elastic energy, generally, the $\{110\}$ and $\{111\}$ texture components [20]. As a result, the main recrystallized texture components are $<111>/$ ND (normal direction) fiber [18] (also $\gamma$-fiber with $\{111\}<110>$ and $\{111\}$ $<112>$ main texture components).

Nevertheless, recrystallization nuclei can also form in areas with low stored elastic energy when annealed at rapid heating rates [21,22]. High heating rate can reduce the release of stored elastic energy during recovery, increase the driving force for grains nucleation and coarsening, and promote high angle grain boundary migration, which lowers the orientation dependence on recrystallization nucleation [16]. 


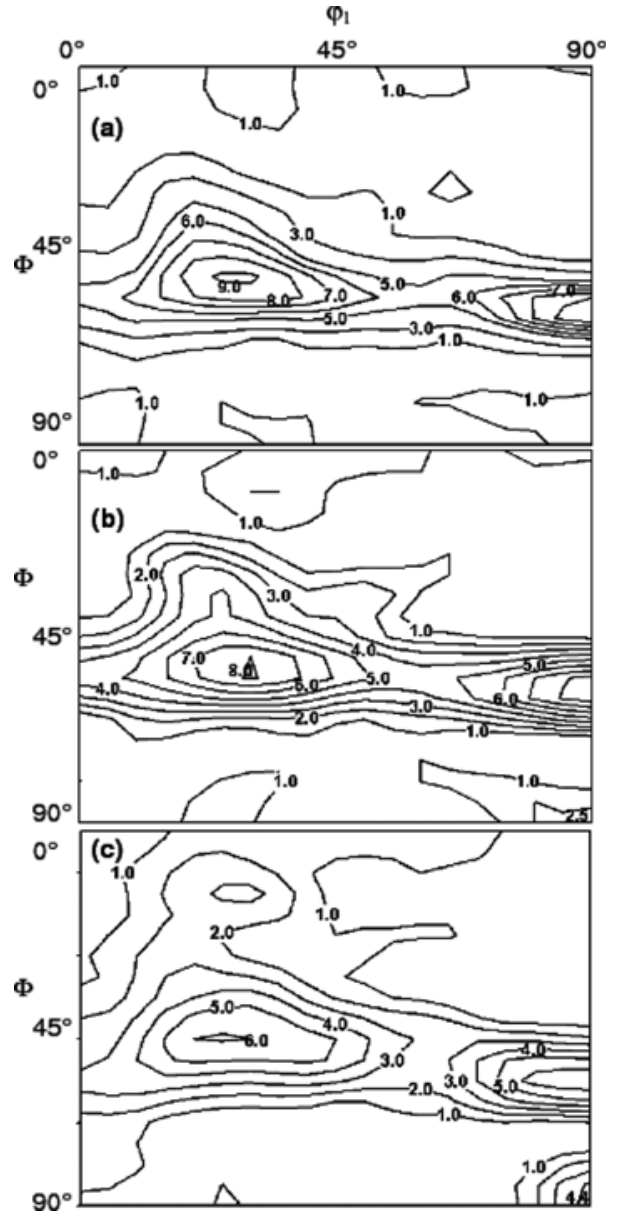

Fig. 4. ODF $\varphi_{2}=45^{\circ}$ section for samples annealed at $880^{\circ} \mathrm{C}$ for $15 \mathrm{sec}$ at various heating rates: (a) $15^{\circ} \mathrm{C} / \mathrm{s}$, (b) $100^{\circ} \mathrm{C} / \mathrm{s}$, (c) $300^{\circ} \mathrm{C} / \mathrm{s}$.

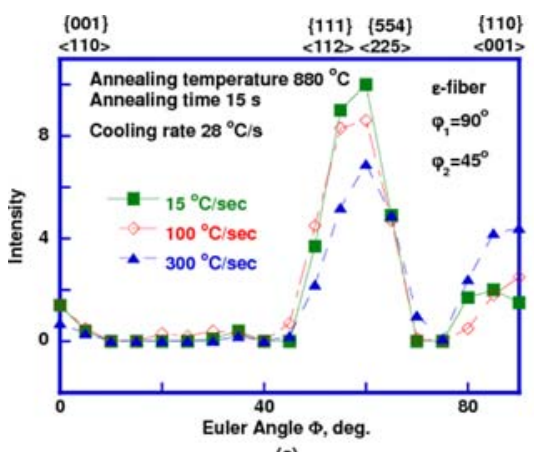

(a)

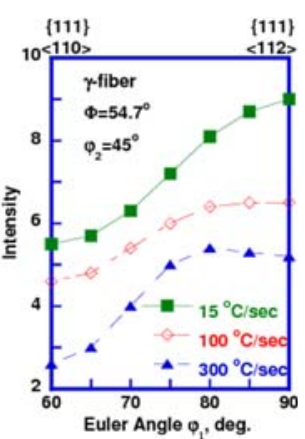

(b)
Fig. 5. Intensity of different fiber textures: (a) $\varepsilon$-fiber texture; (b) $\gamma$ fiber texture.

Finally, this decreases the $<111>/$ ND intensity and increases the intensity of the $\{110\}<001>$ Goss texture component.

The intensities of recrystallized texture components $(\varepsilon-$ fiber and $\gamma$-fiber) are shown in Fig. 5 for various heating rates. As seen in Fig. 5a ( $\varepsilon$-fiber), the $\{110\}<001>$ Goss component is strengthened, while the $\{111\}<112>$ and $\{554\}<225>$ texture components are greatly weakened. Fig. 5b shows that the intensity of $\gamma$-fiber greatly decreases as the heating rate increases from 15 to $300{ }^{\circ} \mathrm{C} / \mathrm{s}$. There are no easy magnetic directions in the $\{111\}$ planes, and the $\{110\}<001>$ (Goss) orientation has $<100>$ easy magnetization direction along the rolling direction $[12,20]$. Texture optimization of nonoriented electrical steels mainly consists of avoiding the occurrence of grains with $<111>/$ ND fiber and generating more grains with $<001>/ / \mathrm{RD}$ and $<001>/ / \mathrm{ND}$ fibers [4]. Thus, rapid annealing is favorable to reduce the $\gamma$-fiber intensity and increase the Goss texture component, which is an effective way to improve magnetic properties.

\subsection{Effect of annealing time on recrystallized texture}

The main composition of recrystallized texture is shown in Fig. 6 for the annealing temperature of $880^{\circ} \mathrm{C}$ at a heating rate of $300{ }^{\circ} \mathrm{C} / \mathrm{s}$, and annealing time varying from 3 to 30 seconds. The intensity of all texture components changes slightly. In general, annealing causes grain growth, which after recrystallization could strengthen the $<111>/ /(\mathrm{ND})$ fiber [23]. Compared with the intensity of the Goss component in Fig. 4a, it increases greatly in Fig. 6. The appearance

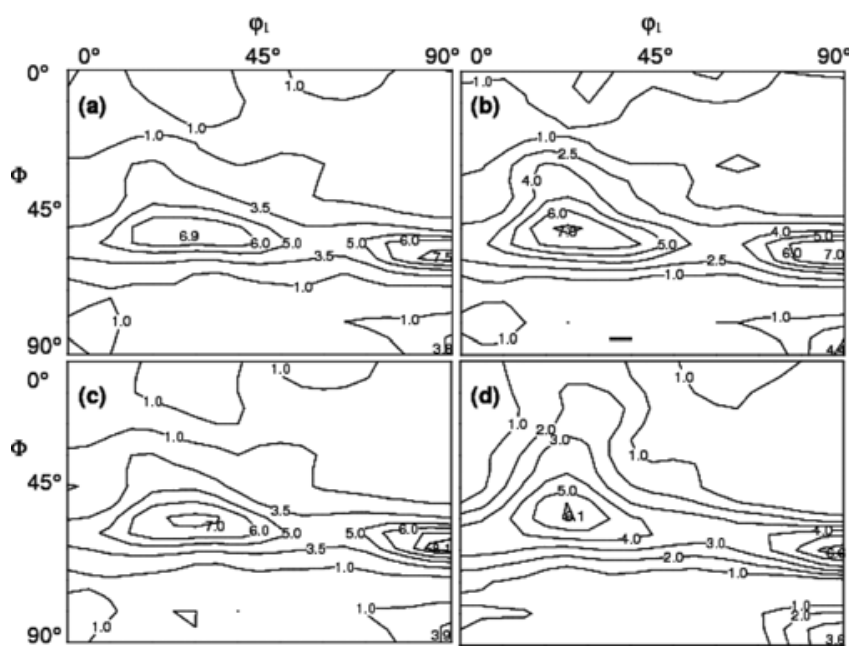

Fig. 6. ODF $\varphi_{2}=45^{\circ}$ section of samples annealed at $880{ }^{\circ} \mathrm{C}$ with various holding times: (a) $3 \mathrm{~s}$, (b) $6 \mathrm{~s}$, (c) $9 \mathrm{~s}$, (d) $30 \mathrm{~s}$.

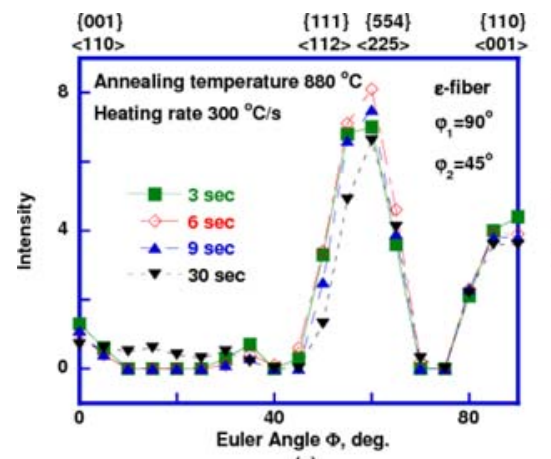

(a)

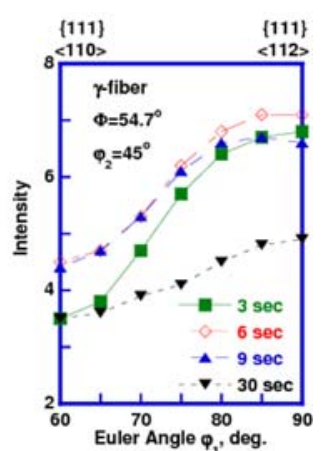

Fig. 7. Intensity of samples with different fiber textures annealed at $880^{\circ} \mathrm{C}$ at a heating rate of $300^{\circ} \mathrm{C} / \mathrm{s}$ : (a) $\varepsilon$-fiber texture, (b) $\gamma$-fiber texture. 
of $\{110\}<001>$ oriented grains is associated with oriented nucleation, which forms preferentially in deformation bands [20].

As seen in Fig. 7a, the $\{110\}<001>$ Goss component is slightly weakened when the annealing time increases from 3 to 30 seconds. In Fig. $7 b$, the intensities of $\{111\}<112>$ and $\{111\}<110>$ components are almost invariable with the annealing time ranging from 3 to 9 seconds, but they decrease from 7 to 4.5 and from 5 to 3.5 , respectively, when the annealing time increases to 30 seconds. Therefore, with a high heating rate, the annealing time could decrease the intensity of the recrystallized texture, including both the favorable Goss component $\{110\}<001>$ and unfavorable $\{111\}<112>$ and $\{111\}<110>$ texture components. The decrease in intensity of the Goss $\{110\}<001>$ component is less than that of the $\{111\}<112>$ and $\{111\}<110>$ components.

\subsection{Annealing temperature effects on recrystallized tex- ture}

Figure 8 shows the texture present at the $\varphi_{2}=45^{\circ}$ section of ODF for annealing temperatures ranging from $880^{\circ} \mathrm{C}$ to $980^{\circ} \mathrm{C}$, a heating rate of $300^{\circ} \mathrm{C} / \mathrm{s}$, and an annealing time of 3 seconds. The main recrystallization texture is $<111>/ / \mathrm{ND}$ fiber ( $\gamma$-fiber), and the peak intensity centers on the $\{111\}$ $<110>,\{111\}<112>,\{554\}<225>$, and $\{110\}<001>$ orientations, respectively. As the annealing temperature increases, the intensity of the $\{001\}<310>$ texture component increases, which belongs to $<001>/ / \mathrm{ND}$ fiber ( $\theta$-fiber) (Fig. $8 \mathrm{a}-\mathrm{d}$ ), which is favorable for the improvement of magnetic properties.

Figure 9a shows the effect of annealing temperature on the intensity of the $\varepsilon$-fiber. First the intensity of the Goss component increases and then decreases with annealing temperature. When annealing occurs at $880^{\circ} \mathrm{C}$ with a slow heating rate
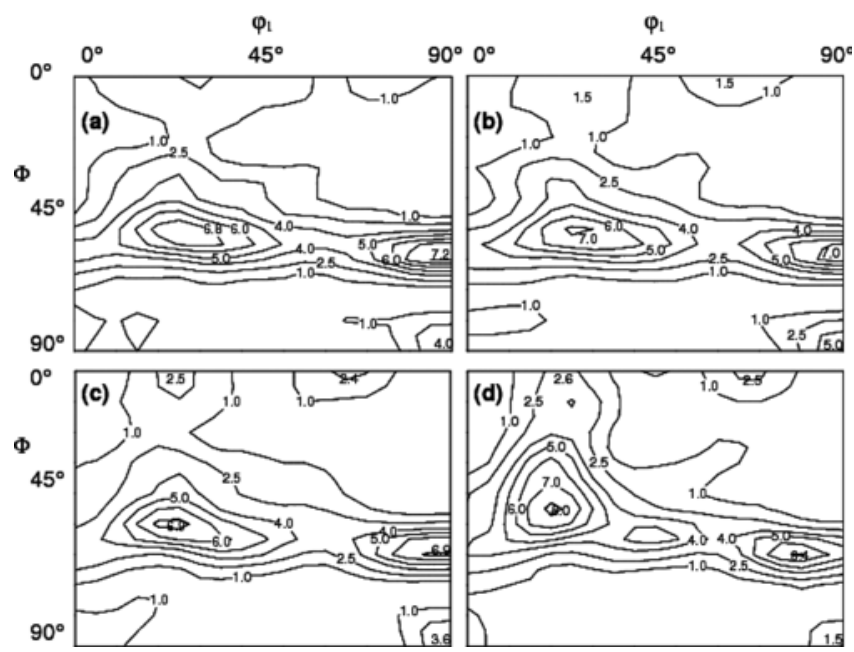

Fig. 8. ODF $\varphi_{2}=45^{\circ}$ section for various annealing temperatures $(3 \mathrm{sec}$ onds hold): (a) $880{ }^{\circ} \mathrm{C}$; (b) $920{ }^{\circ} \mathrm{C}$; (c) $960{ }^{\circ} \mathrm{C}$; (d) $980{ }^{\circ} \mathrm{C}$.
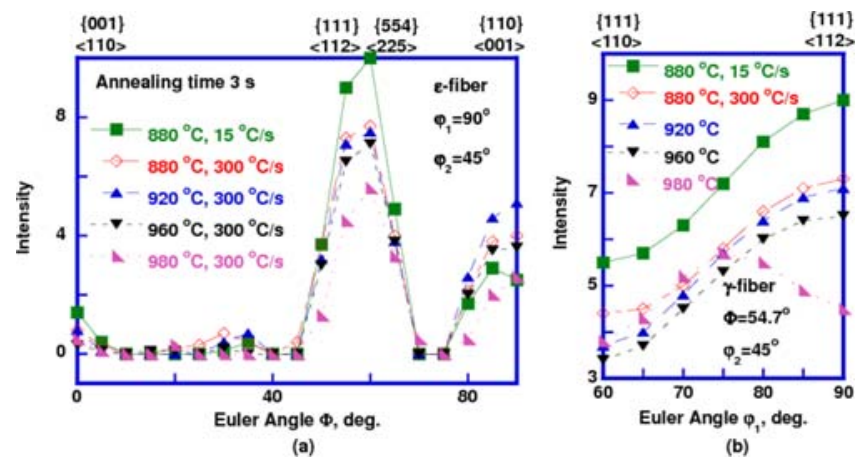

Fig. 9. Effect of annealing temperature on the intensity of different fiber textures with high heating rate $\left(300^{\circ} \mathrm{C} / \mathrm{s}\right)$ : (a) $\varepsilon$-fiber texture (b) $\gamma$-fiber texture.

$\left(15^{\circ} \mathrm{C} / \mathrm{sec}\right)$, the intensities of the $\{111\}<112>$ and $\{554\}$ $<225>$ texture components are 9 and 10 , respectively. When the heating rate is increased to $300^{\circ} \mathrm{C} / \mathrm{s}$, the intensities of the $\{111\}<112>$ and $\{554\}<225>$ texture components decrease to 4.5 and 5.6, respectively, as shown in Fig. 9b. When annealing occurs at $880^{\circ} \mathrm{C}$ for 3 seconds, the intensity of $\gamma$-fiber greatly decreases as the heating rate increases to $300^{\circ} \mathrm{C} / \mathrm{s}$.

In the recrystallization annealing process, most nuclei have highly mobile grain boundaries, while grain boundary motion happens due to the difference in stored elastic energy and the temperature gradient within the neighbor grains [22]. Thus, increasing annealing temperature can improve grain boundary mobility. Therefore, texture changes with annealing temperature are due to the high angle grain boundary migration, unreleased stored elastic energy, increase of the driving force for recrystallization, and rapid grain growth during non-isothermal dynamic heat treatment conditions [24].

\subsection{Annealing effects on magnetic properties}

Figure 10 shows the effect of holding time on the core loss $\left(\mathrm{P}_{1.5 / 50}\right)$ and magnetic induction $\left(\mathrm{B}_{50}\right)$ of samples annealed at $880{ }^{\circ} \mathrm{C}$. Core loss decreases with holding time due to

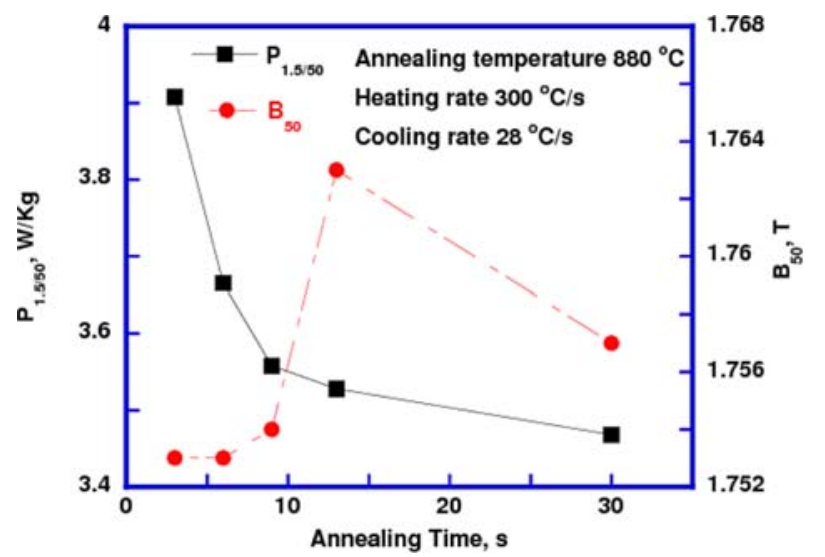

Fig. 10. Effect of holding time on core loss $\left(\mathrm{P}_{1.5 / 50}\right)$ and magnetic induction $\left(\mathrm{B}_{50}\right)$. 


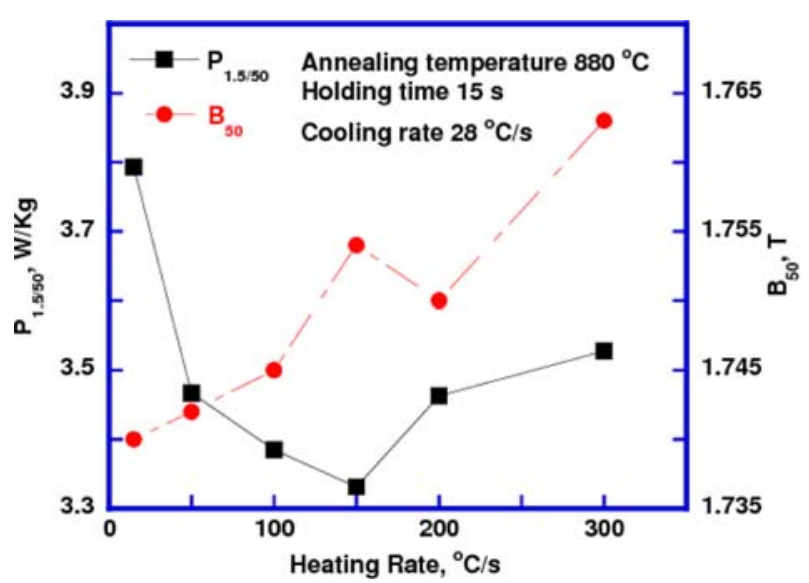

Fig. 11. Effect of heating rate on core loss $\left(\mathrm{P}_{1.5 / 50}\right)$ and magnetic induction $\left(\mathrm{B}_{50}\right)$.

the larger mean grain size, which decreases magnetic hysteresis losses. Magnetic induction increases with holding time, and there is a peak value at 15 seconds. This is due to magnetic induction, which mainly benefits from texture improvement $[4,12]$. The intensities of the $\{111\}<112>$ and $\{554\}<225>$ texture components are similar for both 15- and 30-second holding times (Fig. 5a and Fig. 7a), but the intensity of the Goss component is higher at $15 \mathrm{sec}-$ onds than at 30 seconds.

Figure 11 shows the effect of the heating rate on core loss and magnetic induction. Magnetic induction improves as the heating rate is increased from 15 to $300^{\circ} \mathrm{C} / \mathrm{s}$. This is due to the recrystallized texture optimization caused by rapid heating. Core loss decreases as the heating rate is increased from 15 to $100^{\circ} \mathrm{C} / \mathrm{s}$; however, core loss increases when the heating rate is higher than $100^{\circ} \mathrm{C} / \mathrm{s}$. This is because the mean grain size decreases with the heating rate, which can decrease the classical eddy loss but increase the hysteresis loss.

Figure 12 shows the effect of annealing temperature on

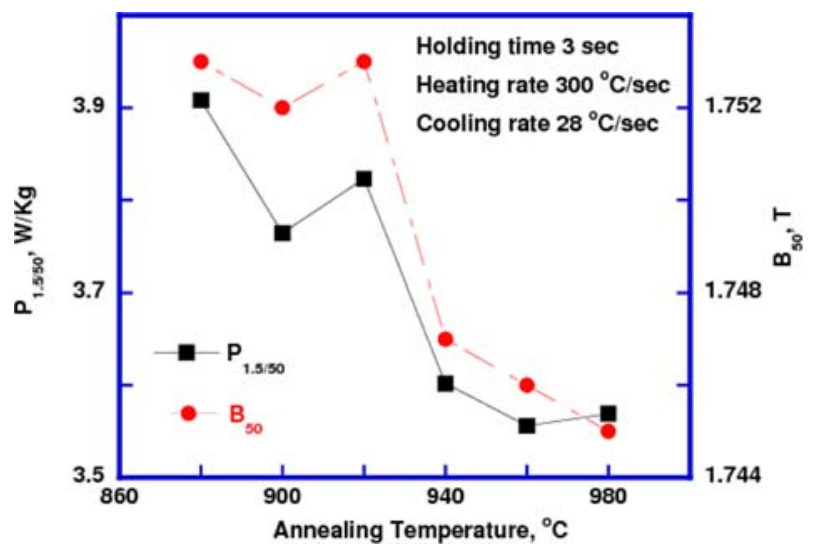

Fig. 12. Effect of annealing temperature on core loss $\left(\mathrm{P}_{1.5 / 50}\right)$ and magnetic induction $\left(\mathrm{B}_{50}\right)$. core loss and magnetic induction with a holding time of 3 seconds and a heating rate of $300{ }^{\circ} \mathrm{C} / \mathrm{s}$. Both the magnetic induction and the core loss decrease when the annealing temperature is increased from $880^{\circ} \mathrm{C}$ to $980^{\circ} \mathrm{C}$ due to the mean grain size increase. The decrease in magnetic induction is consistent with the changes of preferred orientations to magnetic properties in the recrystallized microstructure as seen is Fig. 8. The peak value of magnetic induction appears at $920^{\circ} \mathrm{C}$, which agrees with the higher intensity of the Goss texture component (Fig. 9a). As a result of the final annealing process optimization, the core loss decreased by $13.2 \%$, and the magnetic induction increased by $2 \%$. To improve magnetic properties through grain size and texture component optimization, the annealing temperature should be increased accordingly when rapid heating rates are applied.

\section{CONCLUSIONS}

The effects of rapid annealing (with heating rates ranging from 15 to $300{ }^{\circ} \mathrm{C} / \mathrm{s}$ ) on the recrystallized grain size and texture of non-oriented electrical steel have been investigated to improve its magnetic properties. Based on the experimental results the following conclusions can be drawn:

1. Recrystallized grains could be refined due to the high recrystallization nucleation rates caused by higher heating rates. The trend of grain refinement is more obvious at lower annealing temperatures. Mean grain size optimization $(60$ to $80 \mathrm{~mm})$ was achieved by increasing the annealing temperature $\left(920^{\circ} \mathrm{C}\right.$ to $940{ }^{\circ} \mathrm{C}$ range) at a higher heating rate $\left(300^{\circ} \mathrm{C} / \mathrm{s}\right)$.

2. The recrystallization texture of non-oriented electrical steels could be greatly optimized by increasing the heating rate, which reduces the fraction of $<111>/$ ND g-fiber and increases the fraction of the $\{110\}<100>$ Goss component. The heating rate has a great effect on the recovery, recrystallization, and grain growth processes, which all can lower the orientation dependence on recrystallization nucleation. In this paper, texture optimization was achieved by annealing at $920^{\circ} \mathrm{C}$ to $940{ }^{\circ} \mathrm{C}$ for 6 to 9 seconds at a heating rate of $300^{\circ} \mathrm{C} / \mathrm{s}$.

3. There are appropriate annealing temperatures $\left(920^{\circ} \mathrm{C}\right.$ to $940^{\circ} \mathrm{C}$ ) and annealing time ( 6 to 9 seconds) ranges at a high heating rate of $300^{\circ} \mathrm{C} / \mathrm{s}$, which simultaneously can optimize the core loss and magnetic induction. Magnetic properties and the grade of non-oriented electrical steel were improved by rapid annealing.

\section{ACKNOWLEDGMENTS}

The authors gratefully acknowledge the support provided by the National Natural Science Foundation of China (No. 50874010, No. 50802008), Key Projects in the National Science \& Technology Pillar Program of China (No. 
2009BAE74B00) and the Program for New Century Excellent Talents in University (NCET). Alex A. Volinsky would like to acknowledge support from NSF under CMMI-0600266 grant.

\section{REFERENCES}

1. O. Fischer and J. Schneider, J. Magn. Magn. Mater. 254255, 302 (2003).

2. O. Yoshihiko, K. Masaaki, and H. Atsuhito, J. Magn. Magn. Mater. 320, 2430 (2008).

3. P. R. Kumar, I. Samajdar, N. N. Viswanathan, V. Singal, and V. Seshadri, J. Magn. Magn. Mater. 264, 75 (2003).

4. M. A. Cunha and S. C. Paolinelli, J. Magn. Magn. Mater. 320, 2485(2008).

5. G. Bertotti, J. Magn. Magn. Mater. 320, 2436 (2008).

6. H. Shimanaka, Y. Ito, K. Matsumura, and B. Hukuda, J. Magn. Magn. Mater. 26, 57(1982).

7. J. T. Park, J. S. Woo, and S. K. Chang, J. Magn. Magn. Mater. 182, 381 (1998).

8. A. M. Guerenu, F. Arizti, M. D. Fuentes, and I. Gutierrez, Acta. Mater. 52, 3657 (2004).

9. K. Verbeken, L. Kestens, and J. J. Jonas, Scr. Mater. 48, 1457 (2003).

10. R. Sebald and G. Gottstein, Acta. Mater. 50, 1578 (2002).
11. D. Moseley, Y. Hu, and V. Randle, Mater. Sci. Eng. A 392, 282 (2005).

12. M. A. Cunha and C. P. Paolinelli, J. Magn. Magn. Mater. 254-255, 379 (2003).

13. P. Baudouina, A. Belhadj, and Y. Houbaert, J. Magn. Magn. Mater. 238, 221 (2002).

14. B. K. Bae, J. S. Woo and J. K. Kim, J. Magn. Magn. Mater. 254-255, 373 (2003).

15. X. Duan, H. Huneus, T. Kochmann, K. Leuridan, R. Kaczmarek, and F. Protat, J. Magn. Magn. Mater. 160, 133 (1996).

16. J. T. Park, J. A. Szpunar, and S. Y. Cha, ISIJ. Int. 43, 1611 (2003).

17. D. Muljono, M. Ferry, and D. P. Dunne, Mater. Sci. Eng. A 303, 90 (2001).

18. R. K. Ray, J. J. Jonas, and R. E. Hook, Int. Mater. Rev. 39, 129 (1994).

19. R. L. Every and M. Hatherly, Texture 1, 18391974.

20. J. T. Park and J. A. Szpunar, Acta. Mater. 51, 3037 (2003).

21. A. C. C. Reis, L. Bracke, R. Petrov, and W. J. Kaluba, ISIJ. Int. 43, 1260(2003).

22. Y. Sidor, F. Kovac, and T. Kvackaj, Acta. Mater. 55, 1711 (2007).

23. M. A. Cunha and S. C. Paolinelli, Mater. Sci. Forum. 467470, 869 (2004).

24. C. Oldani and S. P. Silvetti, Scr. Mater. 43, 129 (2000). 